\title{
Translation and validation of Autism Diagnostic Interview-Revised (ADI-R) for autism diagnosis in Brazil
}

\author{
Tradução e validação da ADI-R (Autism Diagnostic Interview-Revised) para diagnóstico de \\ autismo no Brasil \\ Michele M. Becker', Mário B. Wagner², Cleonice A. Bosa ${ }^{3}$, Carlo Schmidt', Danae Longo ${ }^{5}$, \\ Clarissa Papaleo', Rudimar S. Riesgo ${ }^{6}$
}

\begin{abstract}
Objective: To translate into Brazilian Portuguese the Autism Diagnostic Interview-Revised (ADI-R), an extremely useful diagnostic tool in autism. Methods: A case-control study was done to validate the ADI-R. After being translated, the interview was applied in a sample of 20 patients with autism and 20 patients with intellectual disability without autism, in order to obtain the initial psychometric properties. Results: The internal consistency was high, with $\alpha$ of Crombach of 0.967 . The validity of criterion had sensitivity and specificity of $100 \%$, having as a gold standard the DSM-IV diagnostic criteria. The interview had high discriminant validity, with higher scores in the group of patients with autism, as well as high interobserver consistency, with median kappa of 0.824. Conclusion: The final version of ADI-R had satisfactory psychometric characteristics, indicating good preliminary validation properties. The instrument needs to be applied in bigger samples in other areas of the country.
\end{abstract}

Key words: neurology, pediatrics, autistic disorder, child, adolescent, diagnosis, translating, validation studies.

\section{RESUMO}

Objetivo: Traduzir para o português do Brasil a ADI-R (Autism Diagnostic Interview-Revised), uma ferramenta diagnóstica extremamente útil em casos de autismo. Métodos: Foi realizado um estudo caso-controle para validar a ADI-R. A fim de se obter as propriedades psicométricas iniciais da entrevista, após a tradução, a ADI-R foi aplicada em uma amostra de 20 pacientes com autismo e 20 controles com retardo mental sem autismo. Resultados: A consistência interna foi alta, com um $\alpha$ de Crombach de 0,976. A validade de critério mostrou uma sensibilidade e uma especificidade de 100\%, tendo os critérios diagnósticos do DSM-IV como padrão ouro. A entrevista teve uma alta validade discriminante, com maiores escores no grupo de pacientes com autismo, bem como uma alta consistência entre observadores, com um Kappa médio de 0,824. Conclusão: A versão final da ADI-R teve características psicométricas satisfatórias, indicando boas propriedades preliminares de validação. $O$ instrumento necessita ser aplicado em amostras maiores em outras áreas do país.

Palavras-Chave: neurologia, pediatria, transtorno autístico, criança, adolescente, diagnóstico, tradução, estudos de validação.

The landmark paper in autism came in 1942, when Kanner described a behavioral syndrome in eleven children ${ }^{1}$.

Autism is characterized by three core behavioral manifestations: qualitative deficits in social interaction and communication; repetitive and stereotyped behavior patterns; and restricted interests ${ }^{2}$.
In the 1980s, questionnaires and scales were created in an attempt to standardize the diagnosis and evaluation of children with autism. The Autism Diagnostic Interview-Revised $(\mathrm{ADI}-\mathrm{R})^{3}$ is one of the most detailed instrument. Today, it is considered the gold standard for the diagnosis of autism worldwide ${ }^{4,5}$. The ADI-R is one of the most frequently used

${ }^{1}$ MD, Child Neurologist, Hospital de Clínicas de Porto Alegre (HCPA), Universidade Federal do Rio Grande do Sul (UFRGS), Porto Alegre RS, Brazil;

${ }^{2} \mathrm{MD}$, PhD, Epidemiologist, Professor of Medicine, UFRGS, Porto Alegre RS, Brazil;

${ }^{3}$ PhD, Psychologist, Professor of Psychology, UFRGS, Porto Alegre RS, Brazil;

${ }^{4}$ PhD, Psychologist, Professor of Education, Universidade Federal de Santa Maria (UFSM), Santa Maria RS, Brazil;

${ }^{5}$ PhD, Psychologist, Professor of Education, UFSM, Santa Maria RS, Brazil;

${ }^{6} \mathrm{MD}, \mathrm{PhD}$, Child Neurologist, Professor of Medicine, UFRGS, Porto Alegre RS, Brazil.

Correspondence: Rudimar S. Riesgo; Avenida Juca Batista 8.000 / 415;91780-070 Porto Alegre RS - Brasil; E-mail: rriesgo@terra.com.br

Support: FIPE (Fundo de Incentivo à Pesquisa) - HCPA.

Conflict of interest: There is no conflict of interest to declare.

Received 09 August 2011; Received in final form 01 November 2011; Accepted 09 November 2011 
instrument in research and publications in the autism field ${ }^{6,7}$. Its diagnostic properties and validity are well document$\mathrm{ed}^{4}$. The ADI-R is a useful diagnostic tool in distinguishing between children with autism and children with receptive language disorders ${ }^{8}$. The ADI-R diagnostic classification remains relatively stable over time in prospective studies ${ }^{9}$, although it does not rank the syndrome as mild, moderate or severe forms ${ }^{10}$.

In this study, the authors translated the ADI-R into the Brazilian Portuguese language and validate it as a diagnostic instrument of autism in Brazil. The preliminary validation properties are described.

\section{METHODS}

A case-control study was done in a convenience sample of children from the Hospital de Clínicas de Porto Alegre (HCPA). The inclusion criteria were: 7-18 years of age, diagnosis through the DSM-IV criteria for patients with autism and through the Weschler Intelligence Scale for the group of patients with moderate intellectual disability and no autism. The patients with autism were diagnosed by one of the authors (R.S.R). In the group of patients with intellectual disability, autism was ruled out by the Autism Screening Questionaire $^{11}$. The study excluded patients with sensorial or physical impairment, as well as patients with syndrome-associated diseases. The groups were paired by age.

An informed consent was obtained. This study was approved by the Ethics and Research Committee ( $\left.n^{\circ} 06-539\right)$.

\section{Study tool}

The ADI-R is a standard semi-structured interview, applied to parents and/or caregivers of individuals with possibility of autism ${ }^{12}$.

The ADI-R produces a scoring algorithm that is similar to the diagnostic criteria of CID-10 (World Health Organization, 1992) and DSM-IV ${ }^{3,4}$.

It is comprised of 93 items, 42 of which are able to be ranked into the following four scores with the respective cutoff values for diagnostic purposes. Score A: 10; Score B: verbal 8, non verbal 7; Score C: 3 ; and Score D: $1^{12}$. The answers are transcribed into the interview protocol ${ }^{3,10,12}$.

The instrument provides only three diagnoses: patient with autism, autistic signs without the classic form of the disease, patient without autism.

\section{Statistical analysis}

Cronbach's $\alpha$ reliability coefficient was calculated to evaluate the internal consistency. The interobserver consistency was evaluated using Kappa statistics, and, for this purpose, the possible answers to the questions were grouped into two groups: 0 and 1 (no symptoms and mild symptoms); 2 and
3 (moderate symptoms and severe symptoms). For discriminant validity, the Student's $t$-test was utilized for the interview and Fisher's exact test for the interview items. The validity of criterion was evaluated with sensitivity and specificity measurements, having the DSM-IV diagnostic criteria as the gold standard.

The significance level established for this study was $\mathrm{p}<0.05$.

\section{LOGISTICS}

First, the project was evaluated and authorized by the Western Psychological Services (WPS), the publisher that owns the copyrights of the ADI-R. Then, the purchase of the kit for the instrument translation, the royalty payment and the training to interviewers were arranged. It is important to note that the ADI-R is a diagnostic scale belonging to WPS and that its use requires prior training in a recognized Center by the copyright holder. Its use in Brazil is still restricted to research field.

The ADI-R was translated as earlier proposed ${ }^{13,14}$. Two investigators with fluent English made independent translations of the instrument into Portuguese. After that, a final version was produced, which was translated into English by a translator specialized in translation and retro-translation processes, and later sent for analysis of the interview authors. Then, the final version of the interview was applied to parents and/or caregivers.

The interview was made by one of the other three investigators who had been previously trained, blindfolded to the patient's diagnosis. They filled out the interview protocol and handed it to two of the investigators without the initial part of the protocol containing the identification and information that could affect the study blindness. Then, these two investigators, based on the behavior descriptions, gave the scoring algorithm to each patient. Half of the interviews were submitted to the scoring algorithm filled by the two investigators for the interobserver consistency evaluation.

\section{RESULTS}

The study assessed 20 children and adolescents with autism and 20 with intellectual disability without autism. Both groups presented age ranging from 8 to 16 years, with mean age 11, as well as a predominance of boys, especially in the group of patients with autism (80.0\%; 52.9\%). The mean interview duration was similar in both groups, with 2.69 hours of duration in the patients with autism and 2.77 hours in patients without autism, totaling over 100 hours of interviews. Total intelligence quotient (IQ) in the group of patients with moderate intellectual disability ranged from 40 to 55 , with median value of 51 . 
Table 1. Assessment of discriminant validity of the Autism Diagnostic Interview-Revised Brazilian Adaptation.

\begin{tabular}{lcccccc} 
& \multicolumn{1}{c}{$\begin{array}{c}\text { Autistic } \\
\text { patients } \\
(n=20)\end{array}$} & \multicolumn{2}{c}{$\begin{array}{c}\text { Non-autistic } \\
\text { patients }(n=20)\end{array}$} & Diff & $95 \% \mathrm{Cl}$ \\
\cline { 2 - 5 } & $\mathrm{x}$ & $\mathrm{SD}$ & $\mathrm{x}$ & $\mathrm{SD}$ & & \\
\hline Domain 1 & 24.45 & 3.18 & 6.12 & 4.97 & 18.33 & $15.59-21.08$ \\
Domain 2 & 19.4 & 4.24 & 4.47 & 3.28 & 14.93 & $12.36-17.50$ \\
Domain 3 & 7.9 & 2.65 & 0.94 & 1.24 & 6.96 & $5.59-8.32$ \\
\hline
\end{tabular}

Domain 1: Qualitative impairment in social interaction; Domain 2: Qualitative impairment in communication; Domain 3: Restricted, repetitive and stereotyped behavior patterns; $\mathrm{x}$ : median; SD: standard deviation; $\mathrm{Cl}$ : confidence interval; Diff: difference.
The Cronbach's $\alpha$ reliability coefficient was 0.967 (95\%CI 0.952-0.982). In the evaluation for the validity of criterion, the ADI-R correctly identified all autism cases diagnosed through the DSM-IV criteria, with sensitivity of 100\% (95\%CI 83.2-100.0) and specificity of $100 \%$ (95\% CI 80.5-100.0). In the discriminant validity evaluation, mean scores obtained in each of the three diagnostic domains of the instrument were significantly higher in the group of patients with autism, showing that this instrument can discriminate both groups (Table 1).The discriminant validity of each of the 42 scoring items of the interview was also evaluated. A significantly higher number of score 2 in the group with autism and scores 0 and 1 in the group without autism was obtained, showing that the items are valid as they

Table 2. Assessment of discriminant validity for each item of the Autism Diagnostic Interview-Revised Brazilian Adaptation.

\begin{tabular}{|c|c|c|c|c|c|c|c|}
\hline \multirow{3}{*}{ Item } & \multicolumn{3}{|c|}{ Autistic patients } & \multicolumn{3}{|c|}{ Non-autistic patients } & \multirow{3}{*}{$p$-value } \\
\hline & \multicolumn{3}{|c|}{$\begin{array}{c}(n=20) \\
\text { answers }\end{array}$} & \multicolumn{3}{|c|}{$\begin{array}{c}(n=20) \\
\text { answers }\end{array}$} & \\
\hline & 0 & 1 & 2 & 0 & 1 & 2 & \\
\hline 31 & $10.5 \%$ & $5.3 \%$ & $84.2 \%$ & $82.3 \%$ & $5.9 \%$ & $11.8 \%$ & $<0.001$ \\
\hline 33 & $6.6 \%$ & $6.7 \%$ & $86.7 \%$ & $81.2 \%$ & $18.8 \%$ & $0.0 \%$ & $<0.001$ \\
\hline 34 & $0.0 \%$ & $20.0 \%$ & $80.0 \%$ & $81.2 \%$ & $18.8 \%$ & $0.0 \%$ & $<0.001$ \\
\hline 35 & $0.0 \%$ & $0.0 \%$ & $100.0 \%$ & $81.2 \%$ & $18.8 \%$ & $0.0 \%$ & $<0.001$ \\
\hline 36 & $35.7 \%$ & $14.3 \%$ & $50.0 \%$ & $50.0 \%$ & $37.5 \%$ & $12.5 \%$ & $<0.05$ \\
\hline 37 & $13.3 \%$ & $66.7 \%$ & $20.0 \%$ & $81.2 \%$ & $18.8 \%$ & $0.0 \%$ & $<0.001$ \\
\hline 38 & $35.7 \%$ & $21.4 \%$ & $42.9 \%$ & $100.0 \%$ & $0.0 \%$ & $0.0 \%$ & $<0.001$ \\
\hline 39 & $23.1 \%$ & $7.7 \%$ & $69.2 \%$ & $100.0 \%$ & $0.0 \%$ & $0.0 \%$ & $<0.001$ \\
\hline 42 & $5.6 \%$ & $11.1 \%$ & $83.3 \%$ & $100.0 \%$ & $0.0 \%$ & $0.0 \%$ & $<0.001$ \\
\hline 43 & $0.0 \%$ & $0.0 \%$ & $100.0 \%$ & $94.1 \%$ & $0.0 \%$ & $5.9 \%$ & $<0.001$ \\
\hline 44 & $0.0 \%$ & $0.0 \%$ & $100.0 \%$ & $88.2 \%$ & $0.0 \%$ & $11.8 \%$ & $<0.001$ \\
\hline 45 & $0.0 \%$ & $0.0 \%$ & $100.0 \%$ & $70.6 \%$ & $11.8 \%$ & $17.6 \%$ & $<0.001$ \\
\hline 47 & $0.0 \%$ & $0.0 \%$ & $100.0 \%$ & $41.1 \%$ & $11.8 \%$ & $47.1 \%$ & $<0.001$ \\
\hline 48 & $0.0 \%$ & $0.0 \%$ & $100.0 \%$ & $58.8 \%$ & $29.4 \%$ & $11.8 \%$ & $<0.001$ \\
\hline 49 & $0.0 \%$ & $0.0 \%$ & $100.0 \%$ & $50.0 \%$ & $21.4 \%$ & $28.6 \%$ & $<0.001$ \\
\hline 50 & $0.0 \%$ & $15.8 \%$ & $84.2 \%$ & $81.2 \%$ & $12.5 \%$ & $6.3 \%$ & $<0.001$ \\
\hline 51 & $0.0 \%$ & $6.7 \%$ & $93.3 \%$ & $73.4 \%$ & $13.3 \%$ & $13.3 \%$ & $<0.001$ \\
\hline 52 & $0.0 \%$ & $25.0 \%$ & $75.0 \%$ & $64.3 \%$ & $14.3 \%$ & $21.4 \%$ & $<0.001$ \\
\hline 53 & $0.0 \%$ & $0.0 \%$ & $100.0 \%$ & $58.8 \%$ & $5.9 \%$ & $35.3 \%$ & $<0.001$ \\
\hline 54 & $0.0 \%$ & $12.5 \%$ & $87.5 \%$ & $81.2 \%$ & $12.5 \%$ & $6.3 \%$ & $<0.001$ \\
\hline 55 & $0.0 \%$ & $17.6 \%$ & $82.4 \%$ & $46.1 \%$ & $30.8 \%$ & $23.1 \%$ & $<0.001$ \\
\hline 56 & $5.2 \%$ & $5.3 \%$ & $89.5 \%$ & $64.3 \%$ & $14.3 \%$ & $21.4 \%$ & $<0.001$ \\
\hline 57 & $0.0 \%$ & $29.4 \%$ & $70.6 \%$ & $60.0 \%$ & $33.3 \%$ & $6.7 \%$ & $<0.001$ \\
\hline 58 & $6.7 \%$ & $13.3 \%$ & $80.0 \%$ & $88.2 \%$ & $11.8 \%$ & $0.0 \%$ & $<0.001$ \\
\hline 59 & $0.0 \%$ & $0.0 \%$ & $100.0 \%$ & $81.2 \%$ & $18.8 \%$ & $0.0 \%$ & $<0.001$ \\
\hline 61 & $0.0 \%$ & $16.7 \%$ & $83.3 \%$ & $33.4 \%$ & $33.3 \%$ & $33.3 \%$ & $<0.001$ \\
\hline 62 & $0.0 \%$ & $5.6 \%$ & $94.4 \%$ & $62.5 \%$ & $25.0 \%$ & $12.5 \%$ & $<0.001$ \\
\hline 63 & $5.2 \%$ & $21.1 \%$ & $73.7 \%$ & $80.0 \%$ & $20.0 \%$ & $0.0 \%$ & $<0.001$ \\
\hline $64 / 65$ & $0.0 \%$ & $15.8 \%$ & $84.2 \%$ & $53.3 \%$ & $6.7 \%$ & $40.0 \%$ & $<0.001$ \\
\hline 67 & $30.0 \%$ & $30.0 \%$ & $40.0 \%$ & $94.1 \%$ & $5.9 \%$ & $0.0 \%$ & $<0.001$ \\
\hline 68 & $35.0 \%$ & $20.0 \%$ & $45.0 \%$ & $82.4 \%$ & $17.6 \%$ & $0.0 \%$ & $<0.001$ \\
\hline 69 & $25.0 \%$ & $20.0 \%$ & $55.0 \%$ & $100.0 \%$ & $0.0 \%$ & $0.0 \%$ & $<0.001$ \\
\hline 70 & $30.0 \%$ & $0.0 \%$ & $70.0 \%$ & $70.6 \%$ & $23.5 \%$ & $5.9 \%$ & $<0.001$ \\
\hline 71 & $15.0 \%$ & $80.0 \%$ & $5.0 \%$ & $70.6 \%$ & $29.4 \%$ & $0.0 \%$ & $<0.001$ \\
\hline 77 & $20.0 \%$ & $15.0 \%$ & $65.0 \%$ & $88.2 \%$ & $0.0 \%$ & $11.8 \%$ & $<0.001$ \\
\hline 78 & $25.0 \%$ & $0.0 \%$ & $75.0 \%$ & $82.3 \%$ & $11.8 \%$ & $5.9 \%$ & $<0.001$ \\
\hline
\end{tabular}


Table 3. Interobserver consistency of the Autism Diagnostic Interview-Revised Brazilian Adaptation.

\begin{tabular}{|c|c|c|}
\hline Item & kappa & $p$-value \\
\hline 2 & 0.72 & $<0.01$ \\
\hline 9 & 0.76 & $<0.01$ \\
\hline 10 & 0.82 & $<0.01$ \\
\hline 31 & 0.88 & $<0.01$ \\
\hline 33 & 1 & $<0.01$ \\
\hline 34 & 0.75 & $<0.01$ \\
\hline 35 & 0.78 & $<0.01$ \\
\hline 36 & 0.824 & $<0.01$ \\
\hline 37 & * & * \\
\hline 38 & 0.64 & $<0.01$ \\
\hline 39 & 0.68 & $<0.01$ \\
\hline 42 & 1 & $<0.01$ \\
\hline 43 & 0.89 & $<0.01$ \\
\hline 44 & 1 & $<0.01$ \\
\hline 45 & 1 & $<0.01$ \\
\hline 47 & 0.753 & $<0.01$ \\
\hline 48 & 1 & $<0.01$ \\
\hline 49 & 1 & $<0.01$ \\
\hline 50 & 0.89 & $<0.01$ \\
\hline 51 & 0.76 & $<0.01$ \\
\hline 52 & 0.77 & $<0.01$ \\
\hline 53 & 0.88 & $<0.01$ \\
\hline 54 & 1 & $<0.01$ \\
\hline 55 & 0.89 & $<0.01$ \\
\hline 56 & 0.89 & $<0.01$ \\
\hline 57 & 0.75 & $<0.01$ \\
\hline 58 & 0.62 & $<0.01$ \\
\hline 59 & 0.89 & $<0.01$ \\
\hline 61 & 0.66 & $<0.01$ \\
\hline 62 & 0.89 & $<0.01$ \\
\hline 63 & 0.77 & $<0.01$ \\
\hline $64 / 65$ & 0.89 & $<0.01$ \\
\hline 67 & 0.77 & $<0.01$ \\
\hline 68 & 0.82 & $<0.01$ \\
\hline 69 & 0.47 & $<0.05$ \\
\hline 70 & 0.73 & $<0.01$ \\
\hline 71 & 0.64 & $<0.01$ \\
\hline 77 & 0.89 & $<0.01$ \\
\hline 78 & 0.89 & $<0.01$ \\
\hline 86 & 0.62 & $<0.01$ \\
\hline 87 & 0.77 & $<0.01$ \\
\hline $\mathrm{k}$ med & 0.824 & \\
\hline
\end{tabular}

*Impossible to calculate $\mathrm{k}$. discriminate patients with autism from those with intellectual disability without autism (Table 2). Questions 2, 86, 87, 9 and 10 , although part of the scoring algorithm, were not considered in the discriminant validity evaluation because they are not able to be discriminant.

In the group of children with intellectual disability without autism, 5 (29.4\%) of them reached scoring values in 1 or 2 of the three autism diagnostic domains.

The external consistency was satisfactory in all scoring algorithm items, except for item 37, which did not allow the application of Kappa statistics (Table 3). The median Kappa value was 0.824 .

\section{DISCUSSION}

In Brazil, in the last years, three autism assessment instruments have been translated into Portuguese and validated. The Scale for the Assessment of Autistic Behavior ${ }^{15}$, the Childhood Autism Rating Scale ${ }^{16}$ and the Autism Screening Questionaire $^{11}$.

The ADI-R is considered as one of the "gold standard" methods for autism diagnosis by the international literature ${ }^{4,5}$ and is the most frequently used clinical instrument in studies and publications. Given its importance, it has been translated in several countries, such as Germany, Island, Japan, China, Italy and Spain, and is in translation process in others, as Holland, Norway, Hungary, Sweden, Korea and France.

Our study adopted the model of translation and transcultural validation process described by Sperber ${ }^{14}$, which is one of the most frequently utilized in the literature ${ }^{6,17}$.

The predominance of male patients in the group with autism was not unexpected. According to some authors, the mean reported proportions varies from 3.5 to 4 boys to one girl, sometimes reaching 6 or more ${ }^{18,19}$.

The ADI-R Brazilian Adaptation obtained from our sample showed initial validation properties. These results were similar to those of the original interview and its revised edition, as well as the methodology utilized in the instrument validation, with interview application to two groups of patients $^{3,10}$.

The reliability, also known as consistency, refers to the reproducibility of a measurement and it can be evaluated through several forms. This study evaluated the interobserver consistency, which is the measurement of agreement between two or more observers assessing the same individuals ${ }^{20,21}$. It was measured in the original interview and in its revision by means of the video recorded interviews.

In this study, the investigators made the evaluation in written records, a more practical and cheaper method. According to Menezes and Nascimento ${ }^{20}$, these records immediately show whether the appraisers know the adopted criteria and interpret the records the same way. The Kappa 
statistics is the most frequently method utilized to assess the external consistency; it is a measurement of interobserver agreement, corrected to chance agreement. Kappa values over 0.61 are considered substantial, according to Menezes and Nascimento ${ }^{20}$. In our study, high Kappa values were obtained in 40 of the 42 assessed items. In item 37, which assessed the presence of pronoun reversal, it was not possible to apply the statistic test, as it is an orthogonal matrix and not all cells were filled out. Only item 69 presented a nonsatisfactory value of external consistency $(k=0.471)$. This item assesses the stereotyped use of objects and interest in parts of objects. The authors did not find problems in the retro-translation process of this specific item and suggest that the training on concepts and codes involved in the question might have been insufficient.

The internal consistency of the ADI-R Brazilian Adaptation was fully satisfactory. According to Streiner and Norman $^{22}$, the minimum value of 0.70 for Cronback's $\alpha$ coefficient is recommended to ensure that the items consistently assess the same construct.

This study assessed not o nly the discriminant validity of the instrument, but also each instrument item, as performed in the validation studies of the original $\mathrm{ADI}^{10}$ and its subsequent revision ${ }^{3}$, with satisfactory results, similar to those of the abovementioned studies. Thus, the instrument showed to be able to differentiate patients with autism from patients without autism, although they presented manifestations of the autism spectrum, a phenomenon already known in the clinical practice and that makes the differential diagnosis easier between patients with autism and patients with intellectual disability without autism ${ }^{3,10,23}$.

Our study detected that approximately $30 \%$ of the patients with moderate intellectual disability fulfilled the autism diagnosis criteria in at least one of the three diagnostic domains, a percentage that is very similar to that found by Le Couteur et al..$^{10}$, when creating the ADI.

This study also showed that the Brazilian adaptation of the ADI-R presents validity of criterion as it identified all children with autism diagnosed through the DSM-IV criteria. Such criteria were chosen because it is the most frequently utilized in the clinical practice and considered accurate, as suggested by Blacker and Endicott ${ }^{24}$.

The purpose of this study was to translate and validate the ADI-R into Brazilian Portuguese. Although the initial findings have been positive, precaution should be considered. This study was made with a small sample, using a case-control study design that knowingly can overestimate the psychometric properties of behavioral scales. Finally, the sample was obtained in a restricted area of the country. Regional, social and cultural variations should be assessed in a broader way.

\section{ACKNOWLEDGEMENTS}

We would like to thank the Department of Psychology of the HCPA, especially psychologists Natália Soncini and Letícia Rocha, for their help in the identification of patients in this study with moderate intellectual disability.

\section{References}

1. Kanner L. Autistic Disturbances of Affective Contact. The Nervous Child 1942;2:217-251.

2. DSM-IV-TR, Transtornos Globais do Desenvolvimento. In: Manual Diagnóstico e Estatístico de Transtornos Mentais. 4th ed. Texto Revisado 2002. Porto Alegre: Artmed; 2002:99-103.

3. Le Couteur A, Lord C, Rutter M. Autism Diagnostic Interview-Revised: a revised version of a diagnostic interview for caregivers of individuals with possible pervasive developmental disorders. J Autism Dev Disord 1994;24:659-685.

4. Gray KM, Tonge BJ, Sweeney DJ. Using the autism Diagnostic Interview-Revised and the Autism Diagnostic Observation Schedule with young children with developmental delay: evaluating diagnostic validity. J Autism Dev Disord 2008;38:657-667.

5. Moss J, Magiati I, Charman T, Howlin P. Stability of the autism diagnostic interview-revised from pre-school to elementary school age in children with autism spectrum disorders. J Autism Dev Disord 2008;38:1081-1091.

6. Spence SJ, Sharifi P, Wiznitzer M. Autism spectrum disorder: screening, diagnosis, and medical evaluation. Semin Pediatr Neurol 2004;11:186-195.

7. Gadia CA, Tuchman R, Rotta NT. Autismo e doenças invasivas de desenvolvimento.J Pediatr 2004;80(Suppl 2):S83-S94
8. Mildenberger K, Sitter S, Noterdaeme M, Amorosa H. The use of the $A D I-R$ as a diagnostic tool in the differential diagnosis of children with infantile autism and children with a receptive language disorder. Eur Child Adolesc Psychiatry 2001;10:248-255.

9. Soke GN, Philofsky A, Diguiseppi C, Lezotte D, Rogers S, Hepburn S. Longitudinal changes in Scores on the Autism Diagnostic Interview-Revised (ADI-R) in pre-school children with autism: Implications for diagnostic classification and symptom stability. Autism 2011;15:545-562.

10. Le Couteur A, Rutter M, Lord C, et al. Autism Diagnostic interview: a standardized investigator-based instrument. J Autism Dev Disord 1989;19:363-387.

11. Sato FP, Paula CS, Lowenthal R, et al. Instrument to screen cases of pervasive developmental disorder: a preliminary indication of validity. Rev Bras Psiquiatr 2009;31:30-33.

12. Rutter MA, Le Couteur A, Lord C. Autism diagnostic interview revised manual. Los Angeles: Western Psychological Services; 2003.

13. Guillemin F, Bombardier C, Beaton D. Cross-cultural adaptation of health-related quality of life measures: literature review and proposed guidelines. J Clin Epidemiol 1993;46:1417-1432.

14. Sperber AD. Translation and validation of study instruments for crosscultural research. Gastroenterology 2004;126(Suppl):S124-S128. 
15. Assumpção Júnior FB, Kuczinski E, Gabriel MR, Rocca CC. Escala de avaliação de traços autísticos (ATA): validade e confiabilidade de uma escala para a detecção de condutas autísticas. Arq Neuropsiquiatr 1999;57:23-29.

16. Pereira A, Riesgo RS, Wagner MB. Autismo infantil: tradução e validação da Childhood Autism Rating Scale para uso no Brasil. J Pediatr (Rio J) 2008;84:487-494.

17. Mattos P,Segenreich D,Saboia E, Louzã M,Dias G, Romano M.Adaptação transcultural para o português da escala Adult Self-Report Scale para avaliação do transtorno de déficit de atenção/hiperatividade (TDAH) em adultos. Rev Psiquiatr Clin 2006;33:188-194.

18. Klin A. Autismo e síndrome de Asperger: uma visão geral. Rev Bras Psiquiatr 2006;28(Suppl 1):S3-S11.

19. Johnson CP, Myers SM. Identification and evaluation of children with autism spectrum disorders. Pediatrics 2007;120:1183-1215.
20. Menezes PR, Nascimento AF. Validade e confiabilidade das escalas de avaliação em psiquiatria. In: Gorenstein C, Andrade LHSG, Zuardi AW (Eds). Escalas de avaliação clínica em psiquiatria e psicofarmacologia. São Paulo: Lemos; 2000:23-28.

21. Duhn LJ, Medves JM. A systematic integrative review of infant pain assessment tools. Adv Neonatal Care 2004;4:126-140.

22. Streiner DL, Norman GR. Health measurement scales. A pratical guide to their development and use. Second Edition. New York: Oxford Medical Publications; 1995.

23. Waterhouse L, Wing L, Fein D. Re-evaluating the syndrome of autism in the light of empirical research. In: Dawson G (Ed). Autism: nature, diagnosis and treatment. São Paulo: Lemos; 1989263-281.

24. Blacker D, Endicott J. Psychometric properties: concepts of reliability and validity. In: Rush AJ (Ed). Handbook of psychiatric measures. Washington DC: American Psychiatric Association; 2000:7-14. 